\title{
RESTORATION AND STORAGE PROCEDURES OF A RARE HISTORICAL TEXTILE IN THE MUSEUM OF THE FACULTY OF APPLIED ARTS OF HELWAN UNIVERSITY, EGYPT
}

\author{
Ahmed, H. ${ }^{1}$, Yahia, D. ${ }^{2} \&$ Zidan, Y. ${ }^{1}$ \\ ${ }^{I}$ Conservation department, Faculty of Archaeology, Cairo Univ., Giza, Egypt \\ ${ }^{2}$ The Islamic Art Museum, Supreme Council of Antiquities, Cairo, Egypt \\ E-mail: harbyezzeldeen@cu.edu.eg
}

\begin{abstract}
Historical textiles suffer from deterioration due to exposure to uncontrolled environmental conditions, in museums. This article presents strategies for the conservation and storage processes of historical textiles that have been under uncontrolled storage conditions and display, in Egypt. The object dates back to the Ottoman period. Its dimensions are $62 \times 49.5 \mathrm{~cm}$. The textile object is highly decorated with figures of plant, and is multicolored in red, blue, and black. The textile has various types of deterioration such as dust, blue stain, loss of parts and weakened fiber. The study addresses three objectives: first, documenting the objects by using SEM Documentation, FTIR, EDS, Visual documentation, Biological examination, Photograph documentation was carried out in order to develop a plan of conservation treatment. The effects of cleaning materials on the natural dyes were tested. Second, the conservation treatment processes were done, old conservation repairs were removed, and separated parts were supported. Cleaning included mechanical and wet cleaning. The textile was supported by a new linen fabric. Third, an excellent storage system was established in order to keep the object on the long-term storage.
\end{abstract}

Keywords: Textiles, Ottoman period, Uncontrolled environmental, FTIR, EDS

\section{Introduction}

In uncontrolled Egyptian museums such as that of the Faculty of Applied Arts (Helwan University, Cairo) the historical textile was exposed to many challenges such as oscillate relative humidity (RH), changing temperatures, and exposure to light, air pollution, as well as non-standard storage and display methods. All these factors cause damage and decay in both fibers and dyes which weaken both fibers and dyes، hardens and stains fibers, separates parts and eventually some parts are lost [1-6]. The paper aims to present the strategies for the conservation of historical textiles in Egypt. It shows new methods in the conservation of historic textiles, at least in Egypt. The paper aims at identifying the types of fibers and dyes, stain, dust, and different damages in this object through different ways of investigation. The paper reports the conservation treatment of the object such as cleaning، removing the old adhesive and old restorations, replacing lost parts, fixing separate parts and arranging a new display. 


\section{Description of Object}

A textile objects $111 / 5$ found in the museum of Faculty of Applied Arts (Helwan Univ., Cairo). Its measurements are $62 \times$ $49.5 \mathrm{~cm}$., the object is decorated with plants (flowers and leafs) printed with metal blocks. It also contains a variety of colors such as red, blue, green and
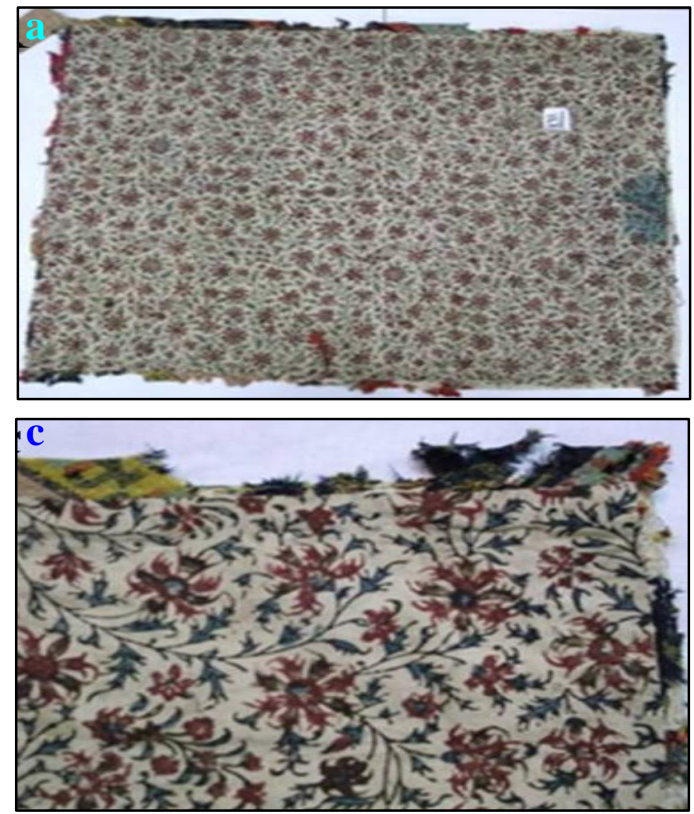

Figure (1) Shows $\underline{\mathbf{a}} \cdot \mathbf{\&} \underline{\mathbf{b}}$. the object from front and back, $\underline{\mathbf{c}}$ \& $\& \underline{\mathbf{d}}$. details of the object (decoration, colors and deterioration aspects).

\section{Documentation and Examination}

One of the main objectives of this study is the scientific documentation of the historical object before the restoration process. Therefore, a variety of documentation approaches were involved: Visual black. There are many signs of damage on this object including separate parts from around edges, loss of parts, weakened fibers, stains and dust. Weave type is plan $1 / 1$ as showing in, as showing in fig. (1)
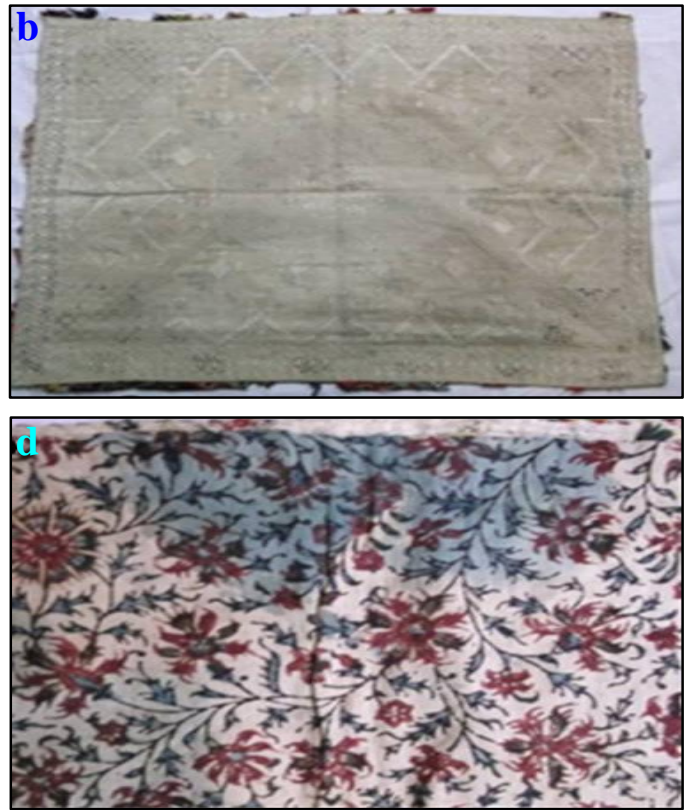

\subsection{Visual and photographic documentation}

The initial visual assessment revealed a poor conservation condition of the object. The textiles were weak and very dirty since they were covered with dust, soil and stains. In general, the object suffered from intensive surface damage that resulted in fiber deformation, missing parts

\subsection{SEM documentation}

Scanning electron microscopy with energy-dispersive $\mathrm{X}$-ray microanalysis (SEM/EDS) is the most frequently used analytical technique to determine the chemical composition. SEM images provide a characteristic surface morphology and are useful for judging the surface structure of the investigated sample, its fiber quality as and photographic documentation, SEM documentation, EDX analysis, Fouriertransform infrared spectral analysis (FTIR), testing the stability of dyes, biological examination [7].

and holes especially along the objects edges. The fringes were weak and suffered from abrasive damage and tearing [8,9]. Furthermore, ahigh-resolution digital camera was used in documentation of the object before, during, and after the conservation process.

well as its damage aspects. A combination of transmitted light microscope and SEM was used to reveal diagnostic features of the fibers, necessary for their identification. Small samples were taken from the object from different parts and investigated under SEM. This technique shows the quality of the fibers as well as the damage aspects 
on these fibers. The surface morphology of the fibers was investigated using a Joel-Scanning Electron Microscope [10, 11]. Figure. (2-a, b) show the SEM of object, its weave type, and type of fibers
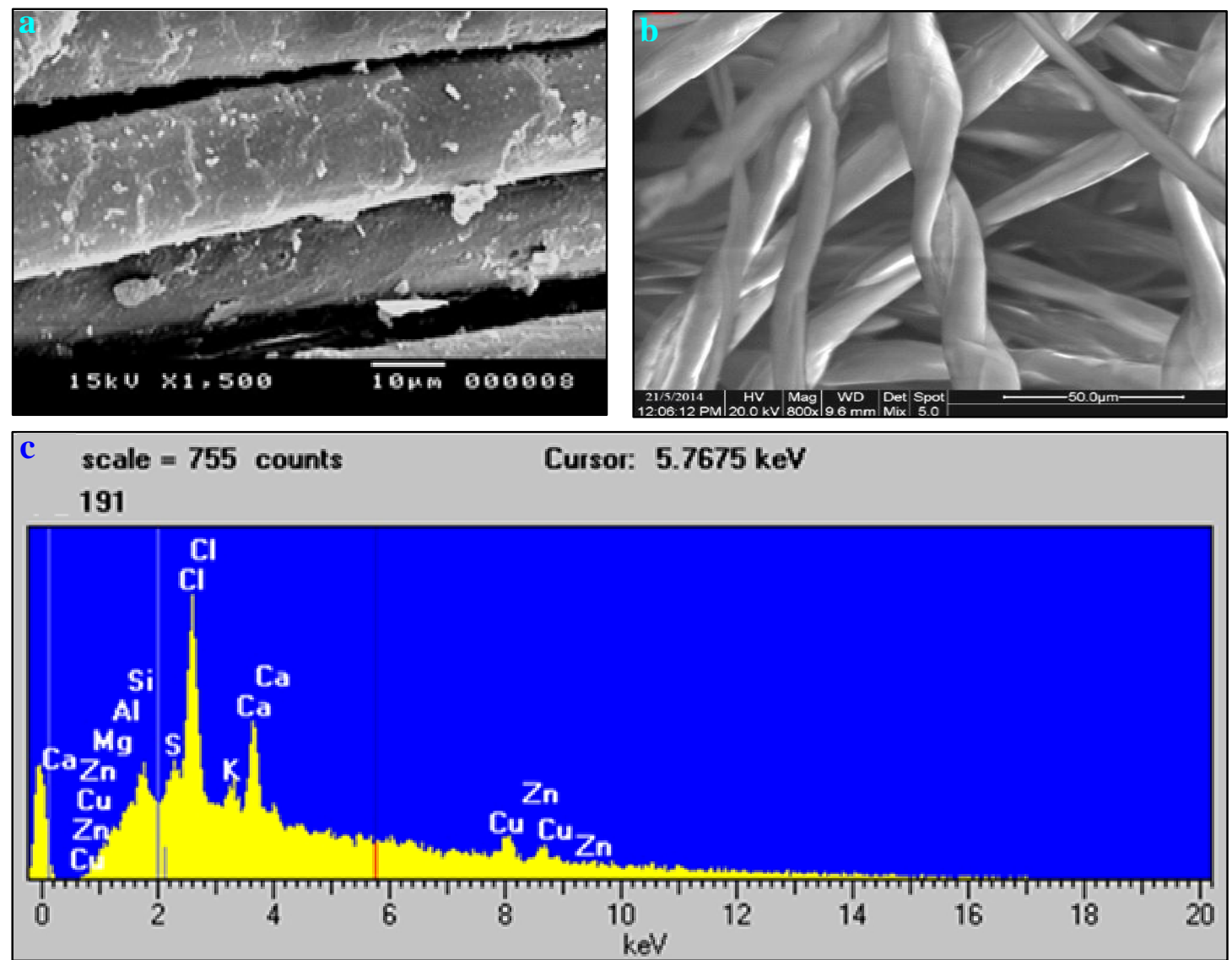

Figure (2) Shows the SEM image of the object a. the type of wool fiber in the strip around the textile, $\underline{\mathbf{b}}$. the body of textile is cotton, $\underline{\mathbf{c}}$. EDX chart of the dirt and stains

\subsection{Fourier-transform infrared spectral analysis (FTIR)}

The FTIR spectra obtained using a BRUKER-FTIR- TENSOR 27 Spectrometer. An expanded spectrum in the 4000 $400 \mathrm{~cm}^{1}$ range used for measuring several factors with a spectral resolution of $4 \mathrm{~cm}^{1}$. Each spectrum was the result of an average of 16 scans. FTIR analysis of solid phase samples can be typically performed using two different methodologies. The first, more traditional and widely used approach is FTIR-KBr which utilizes a pellet of potassium bromide $(\mathrm{KBr})$ that is transparent in the mid-infrared region as a support medium for the sample. The mixture is usually ground with an agate mortar and pestle and subjected to a vacuum pressure of 10 tons. The second, more recent approach is termed FTIR-ATR, which utilizes an attenuated total reflection (ATR) accessory, which operates by measuring the changes that occur in a very internally reflected infrared beam when the beam hits a sample. An infrared beam directed onto an optically dense crystal with a high refractive index at an angle greater than the critical angle for total internal reflection. This internal reflectance creates an evanescent wave that extends beyond the surface of the crystal into the sample held in contact with the crystal. This evanescent wave protrudes only a few microns beyond the crystal surface and into the sample. The vibrational bands that appear in the infrared spectra provide information about the secondary structure of cotton and wool fabrics and inform- 
ation about the chemical functional groups of a sample. This results in a general characterization of the material or the iden- tification of specific comp-ounds as shown in fig. (3) [12-14].
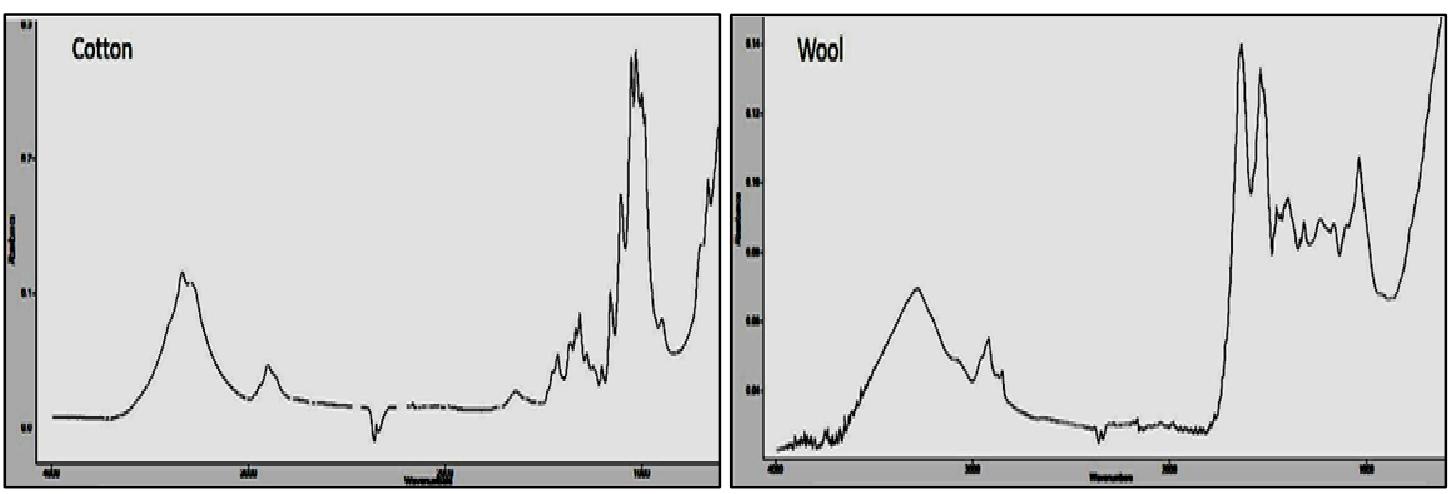

Figure (3) Shows the vibrational bands that appear in the infrared spectra provide information about the secondary structure of Cotton and Wool fabrics by using FTIR.

\subsection{Biological examination}

One important procedure of our conservation is identifying fungi, disposal and removal of fungi, and sterilization of the object. Therefore, swaps from the surface of textile were taken. In addition, a cellulose media was prepared in lab and all the swaps were put in the media for a

week in $27{ }^{\circ} \mathrm{C}$., followed by an examination of fungi under the microscope. Aspregills Niger, Aspregills Flavus and Aspregills famigatus were found and identified on the object as shown in fig. (4) [15-18].
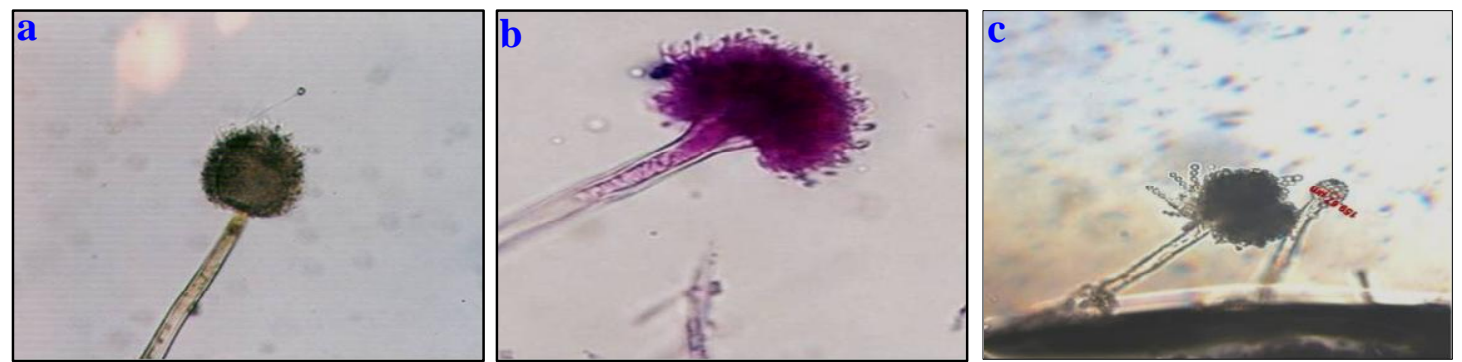

Figure (4) Shows the fungi species affected the object ‥ Aspregills Niger, $\underline{\mathbf{b}}$. Aspregills Flavus, $\underline{\mathbf{c}}$. Aspregills famigatus.

\subsection{Testing the stability of dyes}

The textile object was tested before wet cleaning by puting a piece of cotton around a wooden stick dipped in a cleaning solution and placing it in contact with the colored parts. Each color was indivi-

\section{Restoration Process}

After documentation process, all the data of the object is clear and available for conservators. This data will lead to improve the restoration plan and choosing the mat-

\subsection{Mechanical cleaning}

The aim of this process is to remove harmful soils, which may be disfiguring or cause physical or chemical damage to a textile. The selection of the appropriate cleaning method depends on the nature dually tested. It was found that all the dyes were stable and did not bleed upon contact with the cleaning solution. It was also found that all the dyes were stable and safe to wet-clean $[8,9,19,20]$.

erials for conservation. The next part of the article will discuss the restoration process systematically as following.

of the soil present and on the materials, structure and condition of the textile. Through testing should always be carried out first, to determine the response of the textile to cleaning and to identify 
the most suitable method. Various types of fine brushes are used to remove free dust, dirt and fragile superficial layers

\subsection{The wet cleaning procedure and drying process}

This cleaning procedure used water with other detergent agents، to assist the cleaning process. The ratio was one part detergent Synperonic N to 100 parts of distilled water. The water was agitated to allow it to penetrate between the fibers to release the dirt particles، for 15 minutes. The bath temperature was $30 \circ \mathrm{C}$. Then a second cleaning bath with distilled water only was applied for 10 minutes again with water agitation, and then a third bath with distilled water only, for 10 minutes as shown in fig. (5a \& b). The wet cleaning reduced the soiling, relaxed the fibers, removed the creasing and brightened the colors [23, 24]. of corrosion. Aerobic aspiration of dust was done by using a vacuum cleaner [21, 22].
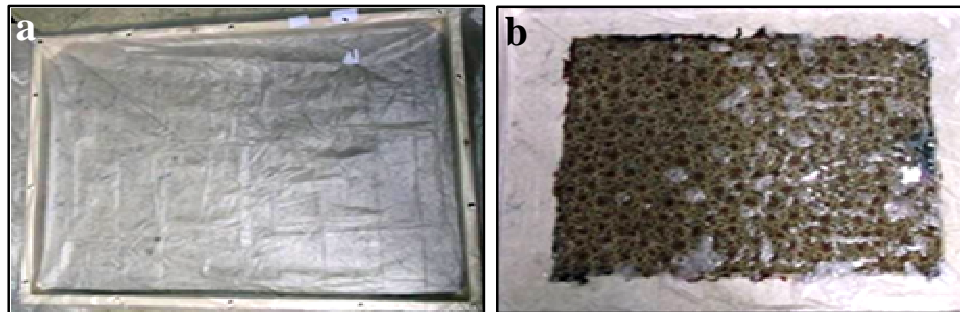

The drying process of wet textiles can provide an opportunity to realign distorted fibers. The water acts as a lubricant reducing the stress of the fibers and allowing the straightening of the yarns with minimum risk. Blocking and drying are considered a crucial part of wet cleaning process. To proceed with the next stage -drying- a table was prepared. Then, the textile pieces still wet from the wet cleaning were placed on top of the table and covered with sheets of Japanese papers to absorb any water surplus, fig. (5-c). It should not be forgotten that while wet the textile is soft and can easily be damaged during handling [25].

Figure (5) Shows $\underline{\mathbf{a}} \cdot \mathbf{\&} \underline{\mathbf{b}}$. preparation of the bath cleaning and putting the textile object in cleaning solution, $\underline{\mathbf{c}}$. drying the textile object after wet cleaning with paper

\subsection{Local cleaning process}

Some blue stains of unknown source were found on the object and very reentrance to removing by wet cleaning. Hence, further cleaning was attempted using smooth brushes with mixture from Acetone and water $(2: 1 \mathrm{~V}: \mathrm{V})$. However, this pro-

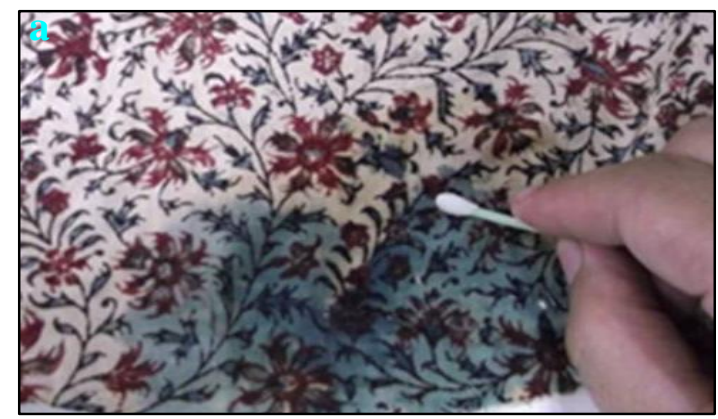

cedure had poor results and the dirt was not completely removed because the textile object began to be damaged so that we stopped the cleaning and washed the place of stain with water and left it to dry, fig. (6) $[25,26]$.

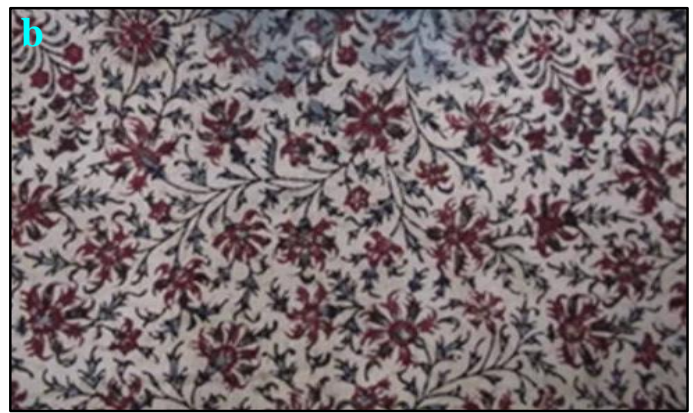

Figure (6) Shows $\underline{\mathbf{a}}$. the local cleaning of object, $\underline{\mathbf{b}}$. the object after cleaning

\subsection{The final support}

In order to prepare the textile for storage, it is necessary to provide the fabric with a new support to increase its strength. For this, a wooden frame prepared by a carpenter from a nearby village to the location of excavations. The wooden frame was later coated with Paraloid B72 (10\% in acetone) to isolate the wood 
from the environmental conditions, minimizing thus the movements of the wooden frame. Later, a new undyed linen support was prepared and washed to remove any chemical residues from the sizing and finishes, and to prevent shrinkage at a later time due to the humidity changes. After washing and drying, the linen was ironed to remove creases and it was then attached to the wooden frame with tacks. Once the new fabric support was prepared, the textile object was placed carefully over the fabric. In mounting, it is important to choose the right materials such as needles and threads to provide the maximum visual satisfaction and to ensure of the future stability without the risk of adverse effects. Usually, conserveators recommend silk threads as the best choice, followed by cotton, viscose rayon or polyester, depending on availability. In this project, a very fine undyed silk thread was used. In the beginning, the object was fixed in the support with wide stitches to preserve its place. Later on, two types of stitches were used: the first type, an overcast stitch, was used to support the edges of the object; and the second type, a running stitch, was used to support the internal areas adjacent to primary stitches and damaged areas. These stitches ensured that the mounted textile was not strained, although they were tight enough to prevent movements or abrasion on the mounting. This type of framing is ensures good support for the object and will reduce future handling to a minimum rate. The mounting is the last stage of the intervenetions, after which the object becomes ready for storing, fig. (7) [27,28].
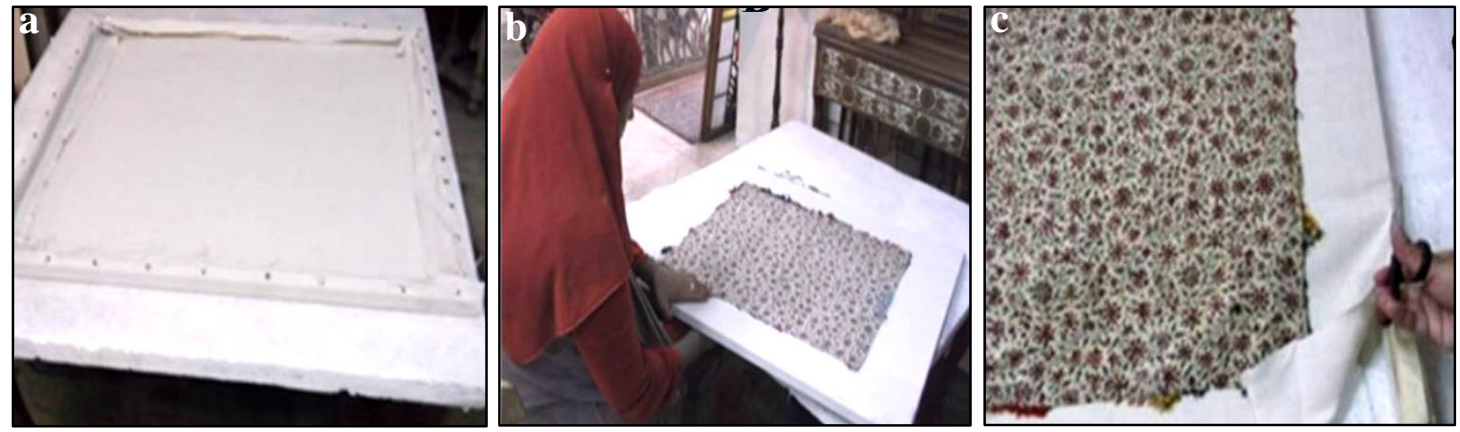

Figure (7) Shows $\underline{\mathbf{a}}$. \& $\underline{\mathbf{b}}$. fixing the textile object after tension the new linen on wooden frame, $\underline{\mathbf{c}}$. removing the new linen from wooden frame and sewing the parties of linen

\section{Storage System}

The main objective of textiles storage method should be to protect the object from the agents of deterioration. The particular method chosen for storing any textile should be based on the textile's condition and size, and all materials that come in direct contact with the object should be of archival quality. After fixing the textile object on the new support, the wooden frame was removed and parties of linen have been sewing. Then we are made box to storage the textile object according to the following steps: Different types of materials were used such as canson foam free acid, white glue, bacrom paper. The dimensions of suggested box are $75 \mathrm{~cm}$ length $\times 25 \mathrm{~cm}$ width $\times$ $20 \mathrm{~cm}$ height. After completion of the cutting increases were definitions the lines on canson foam in order to push up the sides of box. Then white glue was used to stick the sides of box. After drying the glue, the box was covered by bacrom paper from exterior side. Barriers were mad inside the box to fixing the roller on it. The box cover was made with the same previous steps which was $75 \mathrm{~cm}$ length $\times 25 \mathrm{~cm}$ width $\times 10 \mathrm{~cm}$ height, Figure (8) shows the establishing of storage box process [29-32]. The rolled way was selection to storage textile object according to the following steps:

- Put the textile object between freeacid papers.

- Use a free-acid canson tube to roll the object in. 
- Use washed linen to cover the tube and tie it with washed muslin strips.

- Put identification card with the number of the textile object inside the box.
- Put the rolled tube between the barriers inside the box.

- Put acotton pad around the rolled tube.

- Put identification card on the box [33].
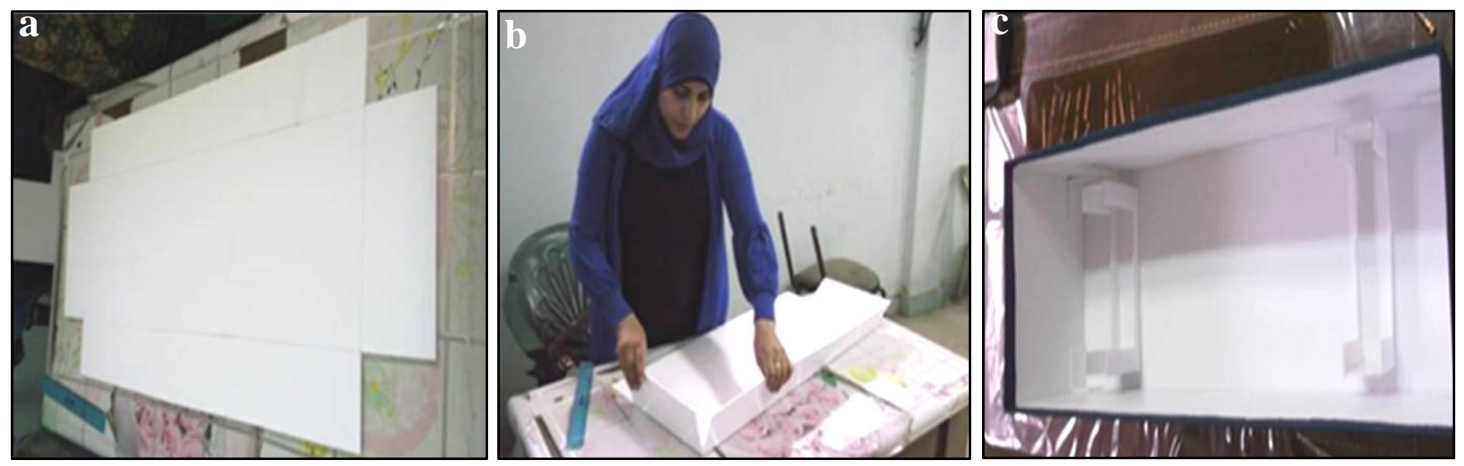

Figure (8) Shows different steps of making the storage box

\section{Conclusion}

This article presents a strategy of restoring and maintaining historical textiles kept in uncontrolled museum environments. Scientific documentation processes using Visual documentation, Optical and SEM Documentation, EDS analysis, Fourier-transform infrared spectral analysis (FTIR), dyes stability test, Biological examination, and Photographic documentation. The documentation revealed a lot of information about the materials used in the manufacture of such textiles. This aided the development of the repair and maintenance plans as well as the selection of materials suitable for the restoration. Restoration and maintenance operations were carried out on the historical piece. An innovative storage style was improvised based on historical textile storage techniques.

\section{References}

[1] Tímár-Balázsy, Á. \& Eastop, D., (1998). Chemical principles of textile conservation, Butterworth-Heinemann, Londan.

[2] Landi, S., (1992). The textile conservator's manual, $2^{\text {nd }}$ ed., ButterworthHeinemann, London.

[3] Ahmed, H., Mohamed W., Saad, H., Nasr, H., Morsy, M. \& Mahmoud, N., (2017). Degradation Behavior of NanoGlue Adhesive due to Historical Textiles Conservation Proces, Egyptian Journal of Chemistry, Vol. 60 (6), pp: 1-12.

[4] Ahmed, H. \& Darwish,S., (2012). Effect of museum conditions on Historical dyed silk fabric with madder dye, Journal of Polymers and the Environment, Vol. 20 (2): pp: 596-606.

[5] Ahmed, H. \& Ziddan, Y., (2011). A new approach for conservation treatment of a silk textile in Islamic Art Museum, Cairo, Journal of Cultural heritage, Vol. 12 (4), pp: 412-419.
[6] Attia, N., Ahmed, H., Yehia, D., Hassan, M. \& Ziddan, Y., (2015). Novel synthesis of nanoparticlesbased back coating flame-retardant materials for historic textile fabrics conservation, Journal of Industrial Textiles, Vol. 46(6), pp: 1379-1392.

[7] Karadag, R., (2014). Some nondestructive and micro-analytical methods for the conservation on textiles from cultural heritage, in: Bomer, W. \& Uhlirz, S., (eds.) $19^{\text {th }}$ Int. Conf. on Cultural Heritage and New Technologies (CHNT), Museen der Stadt Wien, Austria, pp: 33-45.

[8] Ahmed, H., (2014). A new appoach to the conservation of metallic embroidery threads in historic textiles objects from private collection, IJCS, Vol. 5 (1), pp: 21-34.

[9] Ahmed, H., Gremos, S. \& Kolisis, F., (2010). Enzymatic removal of the oily dirt from a coptic tunic using the enzyme Lipase, Journal of Textile 
and Apparel, Technology and Management, Vol. 6 (3), pp: 1-17.

[10] Batcheller, J., (2005). Optical and scanning electron microscopy techniques for the determination of hair fibres from Romano-Egyptian textiles, in: Janaway, R. \& Wyeth P., (eds.) Scientific Analysis of Ancient and Historic Textiles: Informing Preservation, Display and Interpretation, Postprints, $1^{\text {st }}$ Annual Conference, UK, pp: 51-56.

[11] Ahmed, H., Tahoun, F., El-goly, I., Ziddan, Y., (2017). Identification of natural dyes in rare coptic textile using HPLC-DAD and mass spectroscopy in museum of faculty of arts, Alexandria university, Egypt, Dyes and Pigments, Vol. 145, pp: 486-492.

[12] Erra, P. \& Gomez., N., (1996). FTIR analysis to study chemical changes in wool following a sulfitolysis treatment, Textile Research Journal, Vol. 67 (6), pp: 397-401.

[13] West, P. \& Bostrom. M., (2004). Fourier transform infrared spectral analysis of degenerative cartilage: an infrared fiber optic probe and imaging study, Applied Spectroscopy, Vol. 58 (4), pp: 376-381.

[14] Balta, Z. \& Demetrescu, I., (2017). ATR/FTIR investigation into the nature of the metal threads from Roman medieval textile, University Politechnica of Bucharst Scientific Bulletin SeriesC Electrical Engineering and Computer Science, Vol. 79 (2), pp: 25-36.

[15] Kamel, F., Ismael, H. \& Mohammad, S., (2014). Microbial deterioration of historical textiles and approaches for their control, Online Int Interdiscip Res J, Vol. 4, pp. 10-17.

[16] Ljaljević-Grbić, M. \& Stupar., M., (2013). Molds in museum environments: Biodeterioration of art photographs and wooden sculptures, Archives of Biological Sciences, Vol. 65 (3), pp: 955-962.

[17] Mansour, M. \& Ahmed, H., (2012). Occurrence of fungi on some deteriorated ancient Egyptian materials and theircontrolling by ecofriendly products, EJARS, Vol. 2 (2), pp: 91-101.

[18] Gutarowska, B. \& Pietrzak. K., (2017). Historical textiles-a review of microbial deterioration analysis and disinfection methods, Textile Research Journal, Vol. 87 (19), pp: 2388-2406.

[19] Ahmed, H., El-Ebissy. A. \& Richardson, M., (2015). Evaluating study of ultrafast laser-assisted cleaning of historical textiles conservation, Journal of Textile and Apparel, Technology and Management, Vol. 9 (2), pp: 1-15.

[20] Ahmed, H., (2013). Protease enzyme used for artificial ageing on modern cotton fabric for historic textile preservation and restoration, IJCS, Vol. 4 (2), pp: 177-188.

[21] Fiette, A., (1997). Tapestry restoration: An historical and technical survey, The Conservator, Vol. 21 (1), pp: 28-36.

[22] Mason, T., (2016). Ultrasonic cleaning: An historical perspective, Ultrasonics Sonochemistry, Vol. 29, pp: 519-523.

[23] Rifai, M. \& El Hadidi, N., (2010). Investigation and analysis of three gilded wood samples from the tomb of Tutankhamun, In: Dawson, J., Rozeik, C. \& Wright, M. (eds) Decorated Surfaces on Ancient Egyptian Objects, Technology, Deterioration and Conservation, Cambridge, UK, pp: 16-24.

[24] Tímár-Balázsy, Á., (2000). Wet cleaning of historical textiles: surfactants and other wash bath additives, Studies in conservation, Vol. 45 (3), pp: 46-64.

[25] Aslanidou, D., Tsioptsias, C. \& Panayiotou, C., (2013). A novel approach for textile cleaning based on supercritical $\mathrm{CO}_{2}$ and pickering emulsions, The Journal of Supercritical Fluids, Vol. 76, pp: 83-93.

[26] Osman, E., Zidan, Y. \& Fahim, N., (2017). The determination of conservation state of archaeological Moroccan kilim by physical analytical methods, IJCS, Vol. 8 (1), pp: 51-58.

[27] Ahmed, H., (2011). Strategy for preservation of Potlemic warpped mum- 
my's linen in Tuna El-Gabel excavation, Egypt: A case study, IJCS, Vol. 2 (3), pp: 155-164.

[28] Ahmed, H., (2012). First aid of rare Potlemic textile in Tuna El-Gabel excavation, Egypt, e-conservation, Vol. 2, pp: 81-90.

[29] Karimnejad, M., Boyaghchi, M. \& Zolfaghari, B., (2018). Evaluation and optimization of acanthophyllum extract in washing of the historical textiles, Int. J. of Applied Arts Studies, Vol. 2 (4), pp: 7-14.

[30] Abdel-Kareem, O., (2005). The longterm effect of selected conservation materials used in the treatment of museum artefacts on some properties of textiles, Polymer Degradation and Stability, Vol. 87 (1), pp: 121-130.

[31] Quye, A. \& Lennard, F., (2015). Materialising conservation science research for historical textiles, Univeirsty of Glasgow, England.

[32] Abdel-Kareem, O., (2010). Monitoring, controlling and prevention of the fungal deterioration of textile artifacts in the museum of Jordanian Heritage, MAA, Vol. 10 (2), pp: 85-96.

[33] Barlow, A., (2016). Conservation of an early nineteenth-century blockprinted dress: Techniques and historical importance, Fashion Institute of Technology, State University of New York. 